\title{
Comparison of low-carbon pathways for California
}

\author{
Geoffrey M. Morrison ${ }^{1} \cdot$ Sonia Yeh $^{1}$ • Anthony R. Eggert ${ }^{2}$ • \\ Christopher Yang ${ }^{1}$ • James H. Nelson ${ }^{3}$ • Jeffery B. Greenblatt ${ }^{4}$. \\ Raphael Isaac $^{1} \cdot$ Mark Z. Jacobson $^{5}$ • Josiah Johnston ${ }^{6}$. \\ Daniel M. Kammen ${ }^{6} \cdot$ Ana Mileva $^{7}$ - Jack Moore ${ }^{7}$. \\ David Roland-Holst ${ }^{8}$ - Max Wei ${ }^{4}$. John P. Weyant ${ }^{9}$. \\ James H. Williams ${ }^{7,10}$ - Ray Williams ${ }^{11}$ - Christina B. Zapata ${ }^{12}$
}

Received: 11 July 2014 / Accepted: 2 April 2015 /Published online: 29 April 2015

C The Author(s) 2015. This article is published with open access at Springerlink.com

\begin{abstract}
Jurisdictions throughout the world are contemplating greenhouse gas (GHG) mitigation strategies that will enable meeting long-term GHG targets. Many jurisdictions are now focusing on the 2020-2050 timeframe. We conduct an inter-model comparison of nine California statewide energy models with GHG mitigation scenarios to 2050 to better understand common insights across models, ranges of intermediate GHG targets (i.e., for 2030), necessary technology deployment rates, and future modeling needs for the state. The models
\end{abstract}

Electronic supplementary material The online version of this article (doi:10.1007/s10584-015-1403-5) contains supplementary material, which is available to authorized users.

Geoffrey M. Morrison

gmorrison@ucdavis.edu

1 Institute of Transportation Studies, University of California, Davis, CA, USA

2 Policy Institute for Energy, Environment and the Economy, University of California, Davis, CA, USA

3 Union of Concerned Scientists, Berkeley, CA, USA

4 Energy Analysis and Environmental Impacts Department, Lawrence Berkeley National Laboratory, Berkeley, CA, USA

5 Department of Civil and Environmental Engineering, Stanford University, Stanford, CA, USA

6 Energy Resources Group, University of California, Berkeley, CA, USA

7 Energy and Environmental Economics, San Francisco, CA, USA

8 Department of Agricultural and Resource Economics, University of California, Berkeley, CA, USA

9 Department of Management Science and Engineering, Stanford University, Stanford, CA, USA

10 Monterey Institute of International Studies, Monterey, CA, USA

11 Pacific Gas and Electric, San Francisco, CA, USA

12 Civil and Environmental Engineering Department, University of California, Davis, CA, USA 
are diverse in their representation of the California economy: across scenarios with deep reductions in GHGs, annual statewide GHG emissions are 8-46 \% lower than 1990 levels by 2030 and $59-84 \%$ lower by 2050 (not including the Wind-Water-Solar model); the largest cumulative reductions occur in scenarios that favor early mitigation; non-hydroelectric renewables account for $30-58 \%$ of electricity generated for the state in 2030 and $30-89 \%$ by 2050 (not including the Wind-Water-Solar model); the transportation sector is decarbonized using a mix of energy efficiency gains and alternative-fueled vehicles; and bioenergy is directed almost exclusively towards the transportation sector, accounting for a maximum of $40 \%$ of transportation energy by 2050. Models suggest that without new policies, emissions from nonenergy sectors and from high-global-warming-potential gases may alone exceed California's 2050 GHG goal. Finally, future modeling efforts should focus on the: economic impacts and logistical feasibility of given scenarios, interactive effects between two or more climate policies, role of uncertainty in the state's long-term energy planning, and identification of pathways that achieve the dual goals of criteria pollutant and GHG emission reduction.

\section{Introduction}

In 2006, California passed the Global Warming Solutions Act (AB32) which set the limit on greenhouse gas (GHG) emissions at 1990 levels by 2020. California Governors Schwarzenegger and Brown both passed Executive Orders providing further goals of limiting state-wide GHG emissions to at most $20 \%$ of 1990 levels by 2050 . Like many jurisdictions throughout the world with long-term GHG targets, California is now focusing on developing post-2020 climate strategies (CARB 2014). To assist in this process, several research groups have built energy planning models for California that estimate the future trajectories of technologies, fuels, infrastructure, and/or economic impacts (Roland-Holst 2008; Williams et al. 2012; Greenblatt 2015; Jacobson et al. 2014; Nelson et al. 2014; Wei et al. 2014; Yang et al. 2015).

However, policymakers sometimes have difficulty distilling the pertinent insights from energy models because of the diversity of model structures, differences in scenario specifications, opaque underlying assumptions, and medley of model results. In this paper, we perform a comparison of nine California energy planning models with projections to 2050 that include 50 scenarios (including business-as-usual (BAU) and "deep reduction" scenarios ${ }^{1}$ ). Our focus is on the model results and we highlight important model inputs in the Online Resource (OR) 1. Among many benefits, intermodel comparisons can help policymakers by providing a range of conceivable technology deployment rates and GHG trajectories. These comparisons also can be useful to model developers in identifying model deficiencies and future modeling needs.

The outline of this paper is as follows: Section 2 provides the methodology of the comparison and an introduction to the nine models. In Section 3, we examine GHG trajectories, the electricity sector, the transportation sector, biofuel use, air quality, and non-energy emissions. Finally, in Section 4 we provide a discussion on future modeling needs from both the policymaker and model developer perspectives.

\footnotetext{
${ }^{1}$ We define "deep reduction scenarios" as scenarios that achieve one of the following: (1) greater than 75 percent reduction in annual GHG emissions by 2050 relative to 1990 levels, (2) cumulatively similar reductions to those in item 1 by 2050, or (3) $100 \%$ renewable energy penetration by 2050 .
} 


\section{Methodology}

\subsection{Model comparisons}

Past inter-model comparisons fall into two broad categories. The first category, "model discovery," uses common scenario assumptions (or projections) at a specific point in time and compares the behaviors of the models (IPCC 2014a). Perhaps the most well-known and enduring model discovery exercise is the Energy Modeling Forum (e.g., Fawcett et al. 2014). Another type of comparison - as done here - is to use existing model scenarios and projections to synthesize findings across models. These model reviews help identify common insights and deficiencies across modeling platforms but require less coordination than model discovery exercises (e.g., Beaver and Huntington 1992). To our knowledge, ours is the first formal model review of California-specific energy models. This review was not possible until now because many of the models have been developed in the last 2 or 3 years.

To conduct this comparison, we distributed questionnaires to and solicited feedback from 65 policymakers and energy stakeholders on the key topics, practices, and modeling needs in the fall of 2013. We then held a two-day forum in December, 2013 (Morrison et al. 2014). Representation at the forum included high-level individuals from the California Governor's Office, California Air Resources Board, California Energy Commission, electric utilities, public utility commission, and academia. We limited attendance to a relatively small set of stakeholders so that the discussion could be targeted and manageable. The bulk of the work for this paper and the collaboration between modeling teams occurred after the forum. We focused this paper on five topics of greatest interest to the policymakers: electricity, passenger transportation, biofuels, criteria pollutants, and non-energy emissions. Other sectors or topics, such as economic impacts, the industrial sector, or sustainability, were raised as possible dimensions of comparison, but were saved for future exercises.

\subsection{Background on models}

These nine models are scenario-based tools built to understand the merits, constraints, and timing of different mixes of policies, technologies, and energies in the future. All but the Wind, Water, Solar (WWS) model (Jacobson et al. 2014) focus on achieving the state's 2020 and 2050 climate goal. WWS examines the pathway to a $100 \%$ renewable energy system by 2050 . No new scenarios were developed specifically for this model comparison.

The exact composition of future scenarios depends largely on the assumptions, storylines, and analytical underpinnings of the scenarios. Some scenarios in these models emphasize immature technologies such as hydrogen fuel cell vehicles, while others explore shifts in energy service demand (e.g., reduction in vehicle miles traveled), or changes to key input parameters (e.g., price elasticity of energy demand). Because most models have been developed over a number of years and have multiple versions, we limit this comparison to the most recent model version (Table 1) unless otherwise noted.

Table 2 summarizes key characteristics of these nine models. Note that LEAP and SWIT $\mathrm{CH}$ are soft-linked and are typically run together. For this paper, we also reviewed the 2008 and 2014 AB32 Scoping Plan from CARB (2008, 2014) and the CCST-Bioenergy report (Youngs 2013). 
Table 1 Model versions used for this comparison

\begin{tabular}{|c|c|c|c|}
\hline Model & Abbreviation & $\begin{array}{l}\text { Version used in this } \\
\text { comparison }\end{array}$ & Other related versions/resources \\
\hline ARB-VISION & ARB-VISION & CARB (2012) & \\
\hline $\begin{array}{l}\text { Berkeley Energy and } \\
\text { Resources }\end{array}$ & BEAR & Roland-Holst (2008) & Roland-Holst (2011; 2012) \\
\hline $\begin{array}{l}\text { CA Energy Future } \\
\text { Project }\end{array}$ & CCST & $\begin{array}{l}\text { Greenblatt and Long, } \\
\text { (2012) }\end{array}$ & $\begin{array}{l}\text { Youngs (2013) (biofuels-specific } \\
\text { report); CCST (2011) }\end{array}$ \\
\hline CA-TIMES & CA-TIMES & Yang et al. (2015) & McCollum et al. (2012) \\
\hline $\begin{array}{l}\text { CA GHG Analysis of } \\
\text { Policies Spreadsheet } \\
\text { (formerly GHGIS) }\end{array}$ & CALGAPS & Greenblatt $(2015)^{2}$ & Greenblatt and Long (2012) \\
\hline $\begin{array}{l}\text { CA Long-Range Energy } \\
\text { Alternatives } \\
\text { Planning System }\end{array}$ & LEAP & Wei et al. (2014) & Wei et al. (2013) \\
\hline SWITCH & SWITCH & Nelson et al. (2014) & $\begin{array}{l}\text { Fripp (2012); Nelson et al. } \\
\text { (2012); Mileva et al. (2013) }\end{array}$ \\
\hline PATHWAYS & PATHWAYS & Williams et al. (2012) & \\
\hline $\begin{array}{l}\text { Wind, Water, } \\
\text { Solar (WWS) }\end{array}$ & WWS & Jacobson et al. (2014) & $\begin{array}{l}\text { Hart and Jacobson (2011); } \\
\text { www.thesolutionsproject.org }\end{array}$ \\
\hline
\end{tabular}

The models in this paper can be categorized into three broad model structures: optimization, equilibrium, and inventory models (also known as "accounting frameworks"). A model's structure is indicative of both the types of research questions that can be addressed with the model, as well as the caveats to bear in mind when interpreting results. As others have noted (Beaver 1993), heterogeneous model structures make model comparisons more difficult, but also lead to a greater number of insights.

Table 2 Comparison of nine models across multiple dimensions

\begin{tabular}{|c|c|c|c|c|c|c|c|c|c|}
\hline & $\begin{array}{c}\text { ARB- } \\
\text { VISION }\end{array}$ & BEAR & CCST & CA-TIMES & CALGAPS & LEAP & SWITCH & PATHWAYS & wws \\
\hline \multicolumn{10}{|l|}{ Development } \\
\hline \multicolumn{10}{|l|}{ Structure } \\
\hline Sectors modeled & $\begin{array}{c}\text { Transportation, } \\
\text { well-to-tank } \\
\text { electricity }\end{array}$ & All & All & All & All & All but electric & Electric & All & All \\
\hline Solution algorithm & Scenario-based & $\begin{array}{l}\text { Computable general } \\
\text { equilibrium (CGE) }\end{array}$ & Threshold testing & $\begin{array}{c}\text { Optimization } \\
\text { minimizing total } \\
\text { cost or partial } \\
\text { equilibrium }\end{array}$ & Scenario-based & $\begin{array}{c}\text { "Potentials" } \\
\text { analysis }\end{array}$ & $\begin{array}{l}\text { Optimization } \\
\text { minimizing total } \\
\text { energy cost }\end{array}$ & Backcasting & Backcasting \\
\hline Time horizon & $2000-50$ & $2005-50$ & $2010-50$ & $2010-55$ & $2010-50$ & $2010-50$ & $2010-50$ & $2008-50$ & $2010-50$ \\
\hline \multicolumn{10}{|l|}{ Features } \\
\hline \multirow{2}{*}{\multicolumn{10}{|c|}{ Endogenous technology learning }} \\
\hline & & & & & & & & & \\
\hline \multicolumn{10}{|l|}{ Estimates non-energy emissions } \\
\hline \multicolumn{10}{|l|}{$\begin{array}{l}\text { Spatial disaggreg. within CA } \\
\text { Technology stock turnover }\end{array}$} \\
\hline \multicolumn{10}{|l|}{ Economics } \\
\hline \multicolumn{10}{|l|}{$\begin{array}{l}\text { Technology costs/mitigation } \\
\text { costs assessment }\end{array}$} \\
\hline \multicolumn{10}{|l|}{$\begin{array}{l}\text { Measures economic welfare } \\
\text { effects of climate policy }\end{array}$} \\
\hline \multirow{2}{*}{\multicolumn{10}{|c|}{ Other }} \\
\hline Documentation & & & & & & & & & \\
\hline Model available online & & & & & & & & & \\
\hline
\end{tabular}

* WWS does not estimate GHG emissions but its mitigation scenario has an energy portfolio consistent with deep GHG reductions in 2050. 


\section{Comparison}

\subsection{GHG trajectories}

Across models, reference scenarios have a wide range of emissions by 2050: over 800 million metric tonnes $\mathrm{CO}_{2}$-equivalent per year (MMT $\mathrm{CO}_{2} \mathrm{e} /$ year) in the CCST and PATHWAYS

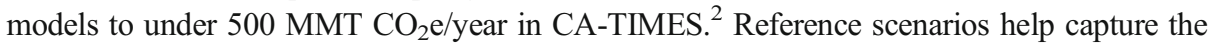
underlying assumptions of the models: for example, the models with the highest GHG trajectories (PATHWAYS and CCST) had 10-20\% higher income and population assumptions by 2050 than more recently developed models, ${ }^{3.4}$

In scenarios that achieve deep reductions in GHGs by 2050, the GHG trajectories also vary widely. Annual emissions decline to 8-46 \% below 1990 levels by 2030 and $59-84 \%$ by 2050, or to 230-396 $\mathrm{MMTCO}_{2} \mathrm{e}$ per year and 68-175 $\mathrm{MMTCO}_{2} \mathrm{e}$ per year, respectively (Fig. 1a). Most deep reduction scenarios have lagged emission reductions, meaning they wait until later years to make the steepest declines in reductions. Rates of change in annual GHG emissions vary between -0.3 and $-5.3 \%$ per year from today to 2030 (average across scenarios of $-1.7 \%$ ), and -0.8 to $-19.9 \%$ per year from 2020 to 2050 (average of $-5.2 \%$ ).

For ease of viewing in Fig. 1a/b, we only show the highest and lowest deep reduction scenario from each model that projects GHG emissions. Also shown are the linear and constant-percent reductions between the $2020 \mathrm{GHG}$ target of $431{\mathrm{MMT} \mathrm{CO}_{2} \mathrm{e} / \text { year }}^{5}$ to the 2050 target of $86 \mathrm{MMT} \mathrm{CO}_{2} \mathrm{e} /$ year (black lines). A linear interpolation was used between time steps. LEAP-SWITCH explores scenarios that achieve greater than $80 \%$ reduction by 2050 , but these scenarios are not presented in this paper, ${ }^{6.7}$

Figure $1 \mathrm{a}$ and $\mathrm{b}$ help demonstrate the importance of early emissions reductions using a side-by-side comparison of annual and cumulative emissions. ${ }^{8}$ For example, CALG APS (S3) only achieves a $59 \%$ emission reduction in annual emissions by 2050 (Fig. 1a) but has the lowest cumulative emissions between 2010 and 2050 (Fig. 1b). Conversely, the PATHWAYS (Hi Renew) scenario achieves an $80 \%$ reduction by 2050 but has the highest cumulative emissions in 2050 due to its lagged reduction schedule. Others have shown that the cumulative emissions of a scenario are a robust indictor for whether that scenario stays below a particular level of global warming (Meinshausen et al. 2009). Of course, Fig. 1a/b use 2050 as the end point - if these trajectories were extended to 2070 the PATHWAYS scenario may have cumulatively lower emissions than the CALGAPS scenario.

\subsection{Power sector}

Between 2001 and 2013, electricity generation in California (including both in-state and net imports before transmission losses) increased from $267 \mathrm{TWh}$ to $296 \mathrm{TWh}$ and the

\footnotetext{
2 see Fig. OR.1 in OR-1 for time trends

${ }^{3}$ See Fig OR.2 and OR.3 in OR-1

${ }^{4}$ Data behind all figures in this paper are available in supplemental spreadsheet (OR-2).

${ }_{6}^{5} \mathrm{CARB}$ recently updated this 2020 value from $427 \mathrm{MMT} \mathrm{CO}_{2} \mathrm{e} /$ year

${ }^{6}$ Two LEAP-SWITCH scenarios make use of bio-power with carbon capture and sequestration (CCS) technology.

${ }^{7}$ WWS does not estimate GHG emissions, but has the highest deployment of renewables of any model by 2050.

${ }^{8}$ Note the start year is 2010 in both figures.
} 
Annual

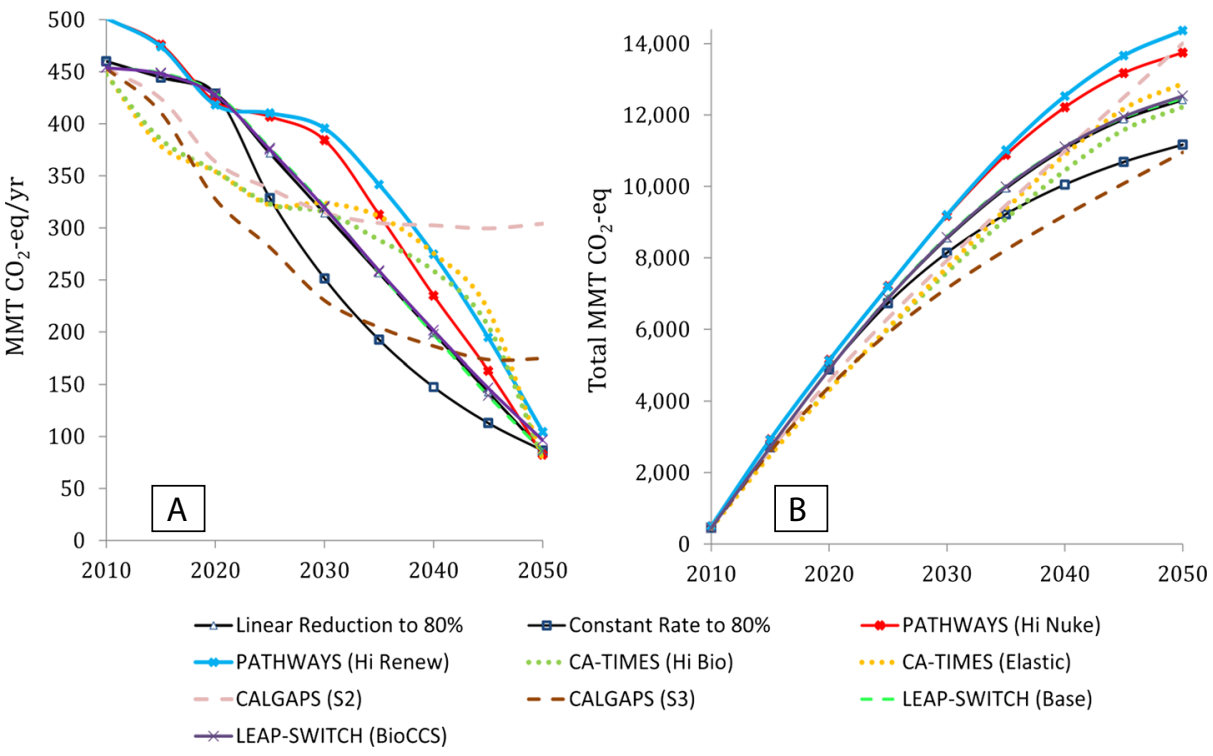

Fig. 1 Annual GHG emissions (1a) in MMT $\mathrm{CO}_{2} \mathrm{e} /$ year and cumulative emissions from 2010 onward (1b) in total $\mathrm{CO}_{2} \mathrm{e}$ for the select deep reduction scenarios (highest and lowest from each model)

corresponding renewable fraction of generated energy increased from 14 to $20 \%,{ }^{9}{ }^{10}$ In the same years, the capacity of the grid powering California expanded from $60.8 \mathrm{GW}$ to $88.5 \mathrm{GW}$ (CEC 2014).

The future expansion of the electricity grid poses both spatial and temporal challenges to energy planners (Hart and Jacobson 2011; Williams et al. 2012; Nelson et al. 2012; Wei et al. 2013). The models examined here differ widely in their geographic scope and resolution. For example, the SWITCH model includes a multi-state region (the Western Electricity Coordinating Council) which allows for optimal solutions across state boundaries. Other models assume a certain fraction of outof-state generation is always available or, like CA-TIMES, assume all power generation after a certain year is generated in-state. SWITCH also is the only model that determines the geographic location and capacity of future power plants and transmission lines. The time dimension also differs widely between models. The models that include time-of-day dispatch models to better understand renewable intermittency problems include CA-TIMES, PATHWAYS, SWITCH, and WWS. ${ }^{11}$

In CCST, SWITCH, ${ }^{12}$ and WWS, demand for electricity is driven exogenously. PATH WAYS estimates demand using a "bottom-up" approach in which the electricity requirements of each individual end-use is first estimated then summed. CALGAPS estimates demand in a

\footnotetext{
${ }^{9}$ see OR-2 for calculations

${ }^{10}$ This percentages include small hydro-electric facilities, large-scale and distributed solar and wind, geothermal, and bioelectricity and does not exactly conform to the state's definition used in its Renewable Portfolio Standard (RPS).

${ }^{11}$ CA-TIMES disaggregates a year into 48 sub-annual time slices (every 2 months in a year and every 3 hours in a day) which is far fewer than a true dispatch model. PATHWAYS uses 12 periods per year. SWITCH uses 144 slices per year or 576 per optimization period (2020, 2030, 2040, 2050). WWS is soft-linked to a least-cost, hourly optimization-dispatch model described in Hart and Jacobson (2011).

12 SWITCH uses exogenous electricity demand values calculated by the LEAP model.
} 
similar way as PATHWAYS, but electricity requirements are determined at the sector level rather than by end use. In CA-TIMES, electricity demand is determined endogenously based on the need to meet the 2050 GHG goal.

Across BAU scenarios, the total power generation from in-state plus imported electricity generation increases by $20-31 \%$ above the 2013 level by 2030 and $45-75 \%$ by 2050 . In all deep reduction scenarios, the electricity grid shifts towards renewable generation - particularly after 2030 - and most end-uses are electrified by 2050 . Because some sectors cannot be electrified or are difficult to decarbonize (e.g., aviation, marine, heavy duty road freight, agricultural fertilizer, etc.), GHG emissions from the electricity grid will likely need to be reduced beyond $80 \%$ (Williams et al. 2012; Nelson et al. 2014; Yang et al. 2015).

As shown in Fig. 2, across deep reduction scenarios the total power generation increases by -2 to $+40 \%$ by 2030 and 8 to $226 \%$ by 2050 , relative to 2013 . For WWS, these increases are much larger: 334 and $465 \%$. The renewable fraction of total generation is $30-58 \%$ by 2030 and 30 $89 \%$ by 2050 , with the majority of new generation coming from wind and solar. For WWS, the renewable fractions are 85 and $100 \%$, respectively. These renewable ranges include small but exclude large hydroelectric generation and therefore are roughly consistent with California's definition of "renewable electricity" in its Renewable Portfolio Standard (RPS). In general, the lower values in these ranges reflect scenarios with greater nuclear and/or CCS deployment. Across scenarios, the implied build-out rate of in-state plus imported renewable electricity (mostly solar and wind) ranges between 0.2 and $4.2 \mathrm{GW}$ per year from 2013 until 2030, with an average of $0.83 \mathrm{GW}$ per year. The renewable build-out rate increases to between 1.5 and 10.4 GW per year from 2030 until 2050, with an average of $3.9 \mathrm{GW}$ per year. Faster rates of grid expansion are assumed in the WWS model: an average of $17 \mathrm{GW}$ of nameplate renewable capacity added per year from 2013 to 2050 to reach $652 \mathrm{GW}$ of total renewable capacity by 2050 . For perspective, from 2001 to 2013 the renewable capacity used by the state (in-state and imported electricity) expanded by $0.67 \mathrm{GW}$ per year while non-renewable capacity expanded by $1.6 \mathrm{GW}$ per year (CEC 2014).

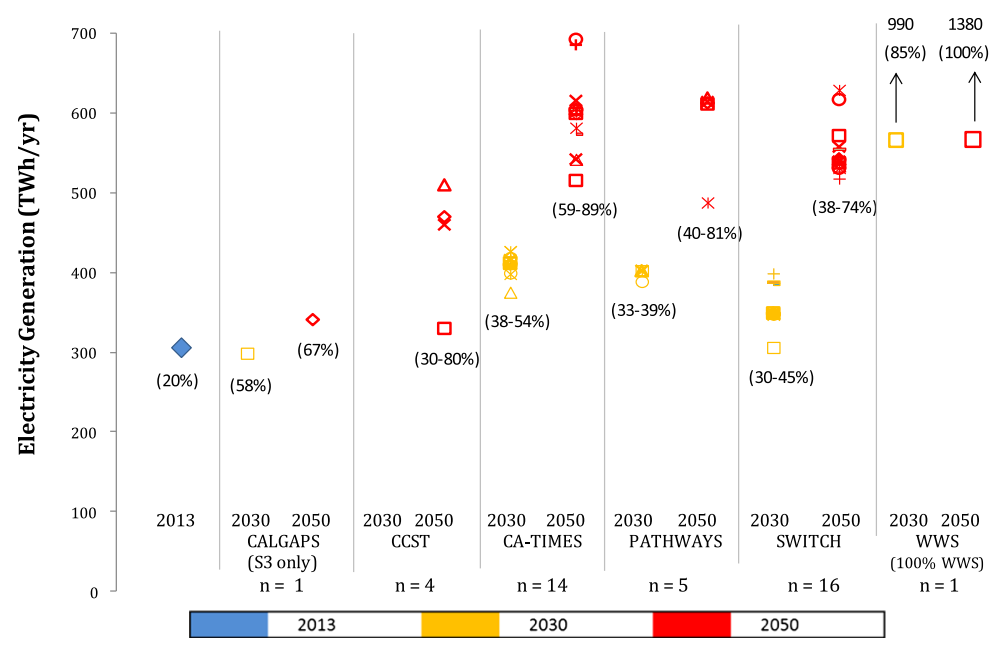

Fig. 22030 and 2050 electricity generation (TWh/year) in deep reduction scenarios. Figure includes in-state production and imported generation. Individual scenarios shown. Percentages below points are percent renewable (excluding large hydro) across mitigation scenarios. Note: CCST did not report 2030 generation 


\subsection{Passenger transportation sector}

A standard practice for modeling the transportation sector in energy models is to make exogenous assumptions about future energy service demand (e.g., statewide vehicle-miles travelled (VMT)) and then allow the model to estimate future fuel mix, vehicle/technology mix, and emissions. The models in this study all follow this practice. The lower the future demand assumptions, the less the need for low-GHG emitting fuels.

For example, in deep reduction scenarios statewide VMT for light-duty vehicles ${ }^{13}$ is assumed to change from 293 billion miles per year in 2010 (CARB 2012) to 226-600 billion miles in 2050. Therefore, the amount of near-zero $\mathrm{CO}_{2} \mathrm{e}$ emission energy used across these models differs widely. Figure 3 shows the passenger light-duty vehicle (LDV) energy projections (stacked columns) and the total transportation sector energy (red triangles) for the model reporting detailed LDV-specific results. Across deep reduction scenarios, total LDV energy use ranges from 8.6 to 25.2 billion gallons of gasoline equivalent (BGGE) in 2030 (1.1-3.3 exajoules (EJ)) and 8.1-19.6 BGGE in 2050 (1.1-2.6 EJ).

With the exception of the PATHWAYS-mitigation scenario, the passenger LDV energy drops from 2010 to 2030, and again from 2030 to 2050 in deep reduction scenarios. This decline results mainly from (1) the underlying assumptions about lower energy service demand in future years and (2) the improved efficiency of LDV technology. Across deep reduction scenarios, petroleum consumption declines $15-72 \%$ by 2030 and $39-100 \%$ by 2050 as the light-duty-vehicle fleet moves primarily to battery electric, plug-in hybrid electric, and hydrogen fuel cell vehicles, although the composition and magnitude of change varies between scenarios. For example, in CA-TIMES the combination of battery electric and hydrogen fuel cell vehicles makes up between 50 and $96 \%$ of the LDV fleet in 2050. In the ARB VISION model's mitigation scenario, these same technologies comprise over $80 \%$ of the LDV fleet in 2050. Regardless of the exact fleet composition, hydrogen and electricity with near-zero lifecycle GHGs (e.g., from wind, solar, biomass, NG with CCS) are needed to power virtually all of the LDV fleet by 2050 .

\subsection{Contribution from bioenergy}

Bioenergy assumptions are important drivers in energy planning models (Wei et al. 2013; Rose et al. 2014). The more "low-carbon" bioenergy assumed to exist, the fewer mitigation strategies that are needed in other sectors and technologies. Across models reviewed here (except WWS), between 4 and 13 billion gallons of gasoline equivalent (BGGE) (0.4-1.7 exajoules) are used in 2050 - up from about 1.0 BGGE today. ${ }^{14}$ Models utilize biomass supply curves from Parker et al. (2010) or De la Torre Ugarte and Ray (2000).

Most models make simple assumptions regarding the carbon content of bioenergy. For example, SWITCH assumes bioenergy has $30 \%$ lower carbon intensity than petroleum-based fuels today and improves to $80 \%$ lower by 2050 . PATHWAYS only includes biomass feedstocks produced in the U.S. that have a "net-zero" carbon intensity ${ }^{15}$ on a lifecycle basis including corn stover, wheat straw, forest residues, forest thinning, and switchgrass (Williams et al. 2012). CA-TIMES assumes a carbon intensity of $75-80 \mathrm{gCO}_{2} \mathrm{e} / \mathrm{MJ}$ for corn ethanol, 25-

\footnotetext{
$\overline{13}$ Light-duty vehicles are typically synonymous with private cars, or passenger vehicles.

${ }^{14}$ see Fig. OR.4 in OR-1

${ }^{15}$ Meaning these biofuels are assumed to exist without GHG emissions
} 


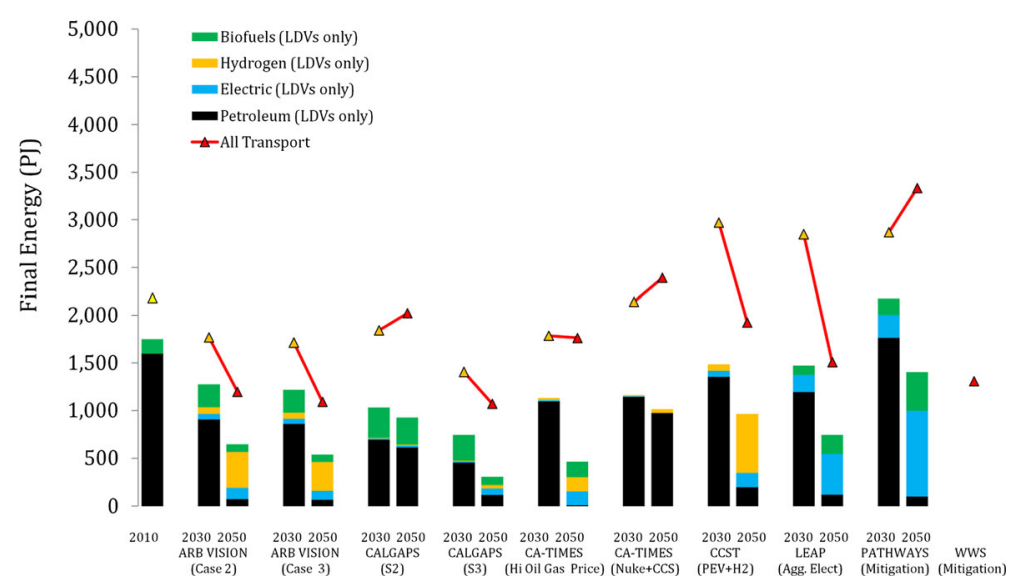

Fig. 3 Passenger LDV energy projections (stacked columns) and the total transportation sector energy (red triangles) for the model reporting detailed LDV-specific results. Note that each fuel provides a different energy intensity of travel (e.g., electric vehicles go 2-3 times as far as a gasoline vehicle per MJ of energy)

$30 \mathrm{gCO}_{2} \mathrm{e} / \mathrm{MJ}$ for cellulosic ethanol, and 13-30 $\mathrm{gCO}_{2} \mathrm{e} / \mathrm{MJ}$ for waste-based or Fischer-Tropsch diesel. CALGAPS estimates net life-cycle GHG emissions for biofuels that include offsets based on the assumed in-state portion of biofuels produced. ARB VISION assumes that the average carbon intensity of all biofuel declines from 67 to $41 \mathrm{gCO}_{2} \mathrm{e} / \mathrm{MJ}$. It should be emphasized that all models here assume point estimates rather than distributions in carbon intensity. A number of studies suggest that these carbon intensities are highly uncertain (e.g., Plevin et al. 2010).

Setting aside this concerns and assuming that bioenergy with low lifecycle GHG emissions will in fact exist in the future, CA-TIMES suggests these fuels are best utilized in the transportation sector (rather than in other sectors). This is mainly because fewer mitigation options are available in the transportation sector compared to other sectors, in particular in aviation, marine, and heavy duty road transport. Across scenarios, bioenergy accounts for a maximum of about $40 \%$ of transportation energy in 2050. Not all long-term energy modeling suggests large quantities of biofuels are needed in the transportation sector. The WWS model, presents a vision of 2050 without bioenergy, relying instead solely on batteries and hydrogen. Biofuel and bioelectricity production with CCS are modeled in sensitivity analyses in the CATIMES and SWITCH models but their results are not presented here.

\subsection{Non- $\mathrm{CO}_{2}$ GHG and criteria emissions}

Reducing non-CO2 GHGs and criteria emissions is a major policy focus in California; however most energy planning models spend relatively little effort on characterizing their future levels. The relative contribution of non-energy and High Global Warming Potential (HGWP) GHGs to overall emissions levels is likely to increase in the coming decades. Greenblatt (2015) and Wei et al. (2013) find that, absent further policy, these emissions alone could exceed the 2050 emission goal.

For criteria emissions, California policymakers are contemplating how to transform the energy system to simultaneously meet GHG targets and the near-term (2023) and midterm (2032) National Ambient Air Quality Standards (NAAQS) for ozone. In particular, meeting 
the 2032 legally-binding NAAQS deadline will be challenging given historical vehicle turnover rates and higher costs of clean technology. CARB (2014) reports that additional strategies, early action, and more rapid development and adoption of zero-emission technologies is needed. How to do this while also meeting GHG targets remains a lively policy debate. Table OR.2 of the OR-1 compares (1) the criteria pollutants estimated by each model and (2) the spatial resolution of these estimations. The table shows that only three of the nine models estimate NOx, ROG, and $\mathrm{PM}_{2.5}$ and none do so at a highly resolute level. ${ }^{16}$

\section{Discussion and conclusions}

Twenty states in the U.S. and the District of Columbia have adopted 2020 and/or longer-term GHG targets (see table OR.3 in the Online Resources for a complete list). While the results from this model comparison are California-specific, the insights may be useful to other jurisdictions that have long-term climate targets or those considering such targets. Our conclusions fall into two broad categories: (1) lessons for policymakers and (2) lessons for model developers and those interested in facilitating model comparisons.

One of the more lucid takeaways for policymakers is the need to consider both annual and cumulative emissions when setting GHG targets and building climate strategies. Scenarios with aggressive and early emission reductions achieve far lower cumulative emissions by 2050. In some BAU scenarios, California has more than twice the cumulative emissions in 2050 as in the mitigation case. From a climate perspective, the obvious implication is that near-term reductions are preferable to delayed reductions (IPCC 2014b).

The model results also highlight how achieving deep GHG emission reductions in the state will require further policy commitments beyond the current policy measures (many of which stop in 2020). Rates of technology transitions in these models - such as deployment of better vehicles or renewable electricity - exceed the historical rates of change in California, often by two or three times. The optimization models (CATIMES, SWITCH) suggest that the least expensive path to make these transitions includes aggressive decarbonization of our electricity supply, electrification of most end-uses, increases in energy efficiency, and deployment of low-carbon transportation fuels and technologies.

Policymakers should also recognize their important role in model development. For example, modelers at the December forum requested more up-to-date information about upcoming policies and more access to the latest state-collected data to improve model calibration/validation and to strengthen analysis of existing and future policies. The December forum also served as a reminder to policymakers about limitations of energy modeling. One cogent example given at the forum was that air quality models adequate for state policy planning and regulation need to be highly spatially-disaggregated whereas most energy models are at the regional or state-level. For example, California's statewide raw emissions inventory had a spatial resolution of $4 \times 4 \mathrm{~km}$ on a Lambert Conformal projection of the earth's surface. The South Coast Air Quality Management District (SCAQMD) raw emissions inventory had a spatial resolution of $5 \times 5 \mathrm{~km}$ on a

\footnotetext{
${ }^{16}$ nitrogen oxides $\left(\mathrm{NO}\right.$ and $\left.\mathrm{NO}_{2}\right) ; \mathrm{ROG}=$ reactive organic gases; $\mathrm{PM}_{2.5}=$ fine $(\leq 2.5 \mu \mathrm{m})$ particulate matter; $\mathrm{SO}_{\mathrm{x}}=$ sulfur oxides
} 
Universal Transverse Mercator (UTM) coordinate system. Exposure assessment studies that seek to measure human health impacts are evaluated at even finer resolutions (e.g., $1 \times 1 \mathrm{~km}$ or at street or block level) (Zapata et al. 2013). Although some integrated assessment models have linked energy projections with air quality to understand cobenefits of climate policies (e.g., McCollum et al. 2013), the resolution of these models is at most $1 \times 1^{\circ}$ (approximately $111 \times 111 \mathrm{~km}$ at the equator). Despite requests from policymakers, attempting to integrate air quality and energy models at a finer resolution may not be practical in terms of model development and computing time.

There are also a number of important lessons for model developers and for those who conduct model comparisons. Yang et al. (2015) report that results of scenarios in CATIMES are highly sensitive to the assumed baseline, technology costs, and availability of breakthroughs (such as advanced bio-liquids, nuclear, and CCS). By treating these drivers of the models with distributions rather than point estimates, one can better understand their impact on the future and design policy to be more robust to potential outcomes.

Additionally, there is a need to better understand the shape of the GHG trajectories between 2020 and 2050 and how the shape contributes to the cumulative cost of scenarios. "Bending" the annual GHG curve downward in early years may provide technological, economic, and risk management options if certain measures prove more difficult than anticipated. However, this has not been adequately researched.

Model developers could also consider standardizing input assumptions in models, such as population, income, elasticities, costs, emission factors, etc. This could be achieved through close coordination between modeling teams, making the models open-source, and by increasing the interoperability between research models and government models used by the state. Greater coherence/transparency of technology adoption/diffusion assumptions, and more extensive data sharing, would likely improve the insights gained from model comparisons. Indeed, having a set of standardized scenarios as done by the Intergovernmental Panel on Climate Change in their Share Socioeconomic Pathways (SSPs) could simplify the often-opaque black boxes of the modeling world (O’Neill et al. 2014).

A final set of lessons for model developers was expressed by policymakers at the December, 2013 forum. Policymakers involved asked for more modeling of: (1) individual policies (i.e., rather than generic climate policies) in order to better understand the spatial, temporal, and socio-economic effects of regulations, (2) interactive effects between two or more policies, (3) non-emission impacts like water, land-use, and economic equity, and (4) the optimal sequencing (i.e., timing) and prioritization of policies and technology deployment. Lastly, policymakers requested that model output be reported in the same metrics as those used in the policy arena. Policymakers specifically requested greater reporting of performance metrics (such as $\mathrm{gCO}_{2} \mathrm{e} /$ mile for vehicles, average $\mathrm{gCO}_{2} \mathrm{e} / \mathrm{MJ}$ for fuels, $\mathrm{gCO}_{2} \mathrm{e} / \mathrm{kWh}$ for electricity, percent renewables by year) and economic metrics (such as $\$ /$ metric ton $\mathrm{CO}_{2} \mathrm{e}$, percent change of household expenditure on energy, and lifecycle costs of travel in $\$ / v e h i c l e$ miles traveled).

Acknowledgments We extend our deep appreciation to Joshua Cunningham, Nicole Dolney, Cody Howard, and Charanya Varadarajan for paper reviews. The authors also wish to thank the members of the Steering Committee of the CCPM forum. Additionally, we had helpful conversations with Mark Delucchi and Mike Kleeman. Lastly, we appreciate the insightful comments from three anonymous reviewers. Any errors contained herein are strictly the responsibility of the authors. 
Open Access This article is distributed under the terms of the Creative Commons Attribution 4.0 International License (http://creativecommons.org/licenses/by/4.0/), which permits unrestricted use, distribution, and reproduction in any medium, provided you give appropriate credit to the original author(s) and the source, provide a link to the Creative Commons license, and indicate if changes were made.

\section{References}

Beaver R (1993) Structural comparison of the models in EMF 12. Energ Policy 21:238-248

Beaver R, Huntington H (1992) A comparison of aggregate demand models for global warming policy analyses. Energ Policy 20:568-574

CARB (2008) Economic evaluation supplement climate change scoping plan pursuant to AB 32

CARB (2012) ARB Vision Model. Available online at: www.arb.ca.gov/planning/vision/vision.htmj

CARB (2014) First update to the climate change scoping plan: building on the framework pursuant to AB 32

CCST (2011) California's Energy Future - The View to 2050. California Council on Science and Technology. Available at: http://ccst.us/publications/2011/2011energy.pdf

CEC (2014) Energy Almanac. Available online at: http://energyalmanac.ca.gov/electricity/

de la Torre UD, Ray DE (2000) Biomass and bioenergy applications of the POLYSYS modeling framework. Biomass Bioenergy 18:291-308

Fawcett AA, Clarke LE, Weyant JP (2014) Q J IAEE Energ Econ E Found 35

Fripp M (2012) Switch: a planning tool for power systems with large shares of intermittent renewable energy. Environ Sci Technol 46:6371-6378

Greenblatt JB (2015) Modeling California policy impacts on greenhouse gas emissions. Energ Policy 78:158-172

Greenblatt JB, Long J (2012) California's Energy Future - Portraits of Energy Systems for Meeting Greenhouse Gas Reduction Requirements, CCST. Available online at: http://ccst.us/publications/2012/2012ghg.pdf

Hart EK, Jacobson MZ (2011) A Monte Carlo approach to generator portfolio planning and carbon emissions assessments of systems with large penetrations of variable renewables. Renew Energy 36:2278-2286

IPCC (2014a) Emissions scenarios. A special report of working group III of the intergovernmental panel on climate change. Cambridge University Press, Cambridge

IPCC (2014b) Chapter 6: assessing transformation pathways. Final draft report of Working

Jacobson MZ, DeLucchi MA, Ingraffea AR, Howarth RW, Bazouin G, Bridgeland B, Burkart, K, Chang M, Chowdhury N, Cook R, Escher G, Galka M, Han L, Heavey C, Hernandez A, Jacobson DF, Jacobson DS, Miranda B, Novotny G, Pellat M, Quach P, Romano A, Stewart D, Vogel L, Wang S, Wang H, Willman L, Yeskoo T (2014) A roadmap for repowering California for all purposes with wind, water, and sunlight. Energy 73:875-89

McCollum D, Yang C, Yeh S, Ogden J (2012) Deep greenhouse gas reductions scenarios for California strategic implications from the CA-TIMES energy-economic systems model. Energy Strat Rev 1:19-32

McCollum D, Krey V, Riahi K, Kolp P, Grubler A, Makowski M, Nakicenovic N (2013) Climate policies can help resolve energy security and air pollution challenges. Clim Chang 119:479-94. http://link.springer.com/ article/10.1007\%2Fs10584-013-0710-y

Meinshausen M, Meinshausen N, Hare W, Raper SC, Frieler K, Knutti R, Frame DJ, Allen MR (2009) Greenhouse-gas emission targets for limiting global warming to 2 degrees. Nature 459:909

Mileva A, Nelson JH, Johnston J, Kammen DM (2013) SunShot solar power reduces costs and uncertainty in future low-carbon electricity systems. Environ Sci Technol 47:9053-9060

Morrison G, Eggert A, Yeh S, Isaac R, Zapata C, Nelson J (2014) California climate modeling dialogue summary report. Social Science Research Network id2403247

Nelson JH, Johnston J, Mileva A, Fripp M, Hoffman I, Petros-Good A, Blanco C, Kammen DM (2012) Highresolution modeling of the western North American power system demonstrates low-cost and low-carbon futures. Energ Policy 43:436-447

Nelson JH, Mileva A, Johnston J, Kammen DM, Wei M, Greenblatt J (2014) Scenarios for deep carbon emissions reductions from electricity by 2050 in Western North America using the SWITCH electric power sector planning model (Vol. II, California's Carbon Challenge Phase 2). California Energy Commission PIER Report

O’Neill B, Kriegler E, Riahi K, Ebi KL, Hallegatte S, Carter T, Mathur R, van Vuuren DP (2014) A new scenario framework for climate change research: the shared socioeconomic pathways. Clim Chang 122:387-400

Parker N, Hart Q et al (2010) Development of a biorefinery optimized biofuel supply curve in the Western United States. Biomass Bioenergy 34:1597-1607

Plevin R, O’Hare M, Jones A, Torn M, Gibbs H (2010) Greenhouse gas emissions from biofuels' indirect land use change are uncertain but may be much greater than previously estimated. Environ Sci Technol 44:8015-21 
Roland-Holst D (2008) Economic Analysis of California Climate Policy Initiatives using the Berkeley Energy and Resources (BEAR) Model (Appendix G-III). Available online at: www.arb.ca.gov/cc/scopingplan/ document/appendices volume1.pdf

Roland-Holst D (2011) More jobs per gallon: how vehicle efficiency fuels growth in California. Research paper 1103011, UC Berkeley

Roland-Holst D (2012) Options for cap and trade auction revenue allocation: an economic assessment for California. Paper 1204231, UC, Berkeley

Rose SK, Kriegler E, Bibas R, Calvin K, Popp A, van Vuuren DP, Weyant JP (2014) Bioenergy in energy transformation and climate management. Clim Chang 123:477-493

Wei M, Nelson JH, Greenblatt JB, Mileva A, Johnston J, Ting M, Yang C, Jones C, McMahon JE, Kammen DM (2013) Deep carbon reductions in California require electrification and integration across economic sectors. Environ Res Lett 8:1-10

Wei M, Greenblatt JB, Donovan SM, Nelson JH, Mileva A, Johnston J, Kammen DM (2014) Non-Electricity Sectors and Overall Scenarios for Meeting 80 \% Emissions Reduction in 2050 (Vol. I, California's Carbon Challenge Phase 2) CEC PIER Report, March 2014. Available online at: http://eetd.lbl.gov/publications

Williams J, DeBenedictis A, Ghanadan R, Mahone A, Moore J, Morrow W, Price S, Torn M (2012) Greenhouse gas emissions cuts by 2050: the pivotal role of electricity. Science 335:53-59

Yang C, Yeh S, Ramea K, Zakerinia S, McCollum DL (2015) Achieving California's 80 \% greenhouse gas reduction target in 2050: technology, policy and scenario analysis using CA-TIMES energy economic systems model. Energ Policy 77:118-130

Youngs H (2013) California's energy future - the potential for biofuels. Publication from the CCST

Zapata C, Muller N, Kleeman M (2013) PM2.5 co-benefits of climate change legislation part 1: California's AB 32. Clim Chang 117:377-397 